\title{
Axial Vascularization of Nano-HA/Collagen/PLA Composites by Arteriovenous Bundle
}

\author{
Hai Wang, ${ }^{1}$ Xiao Chang, ${ }^{1}$ Guixing Qiu, ${ }^{1}$ Fuzhai Cui, ${ }^{2}$ Xisheng Weng, ${ }^{1}$ Baozhong Zhang, \\ Bo Yang, ${ }^{1}$ Xiaojie Lian, ${ }^{2}$ and Zhihong $\mathrm{Wu}^{1}$ \\ ${ }^{1}$ Department of Orthopaedic Surgery, Peking Union Medical College Hospital, No. 1 Shuaifuyuan Hutong, Beijing 100730, China \\ ${ }^{2}$ Department of Materials Science \& Engineering, Tsinghua University, Beijing 100084, China
}

Correspondence should be addressed to Zhihong Wu; wuzh3000@126.com

Received 4 June 2013; Accepted 28 June 2013

Academic Editor: Xiaoming Li

Copyright (c) 2013 Hai Wang et al. This is an open access article distributed under the Creative Commons Attribution License, which permits unrestricted use, distribution, and reproduction in any medium, provided the original work is properly cited.

\begin{abstract}
In previous studies, nano-hydroxyapatite/collagen/poly(L-lactic acid) (nHAC/PLA) composites have been prepared and confirmed to repair small sized bone defects. However, they are restricted to repair a large defect without sufficient oxygen and nutrition for cell survival. The result of this study confirmed that nHAC/PLA composites could be axially vascularized by being implanted intramuscularly with arteriovenous (AV) bundle (Group A) in the groins of rabbits. The combination with autologous bone marrow (Group B) could not enhance it the vascularization in early phase ( 2 weeks, $P>0.05$ ), but it could enhance in middle and later phases $(6$ and 10 weeks, $P<0.01)$. It meant that nHAC/PLA could be prefabricated as a vascularized bone substitute for grafting.
\end{abstract}

\section{Introduction}

Reconstruction of large bone defects poses a major challenge to orthopedists. Despite the development of numerous biological and synthetic bone substitutes, vascularized and nonvascularized autologous bone grafts remain the gold standard for osteogenic bone replacement [1]. The shortcomings and complications of autologous bone grafting including fibula, scapula, or iliac crest restrict its application [2]. Allogenic and xenogenic bone grafts are risk of disease transmission [3]. Tissue engineering and regenerative medicine are promising therapeutic strategies for the repairment or replacement of diseased or injured tissues and organs [4]. Tissue-engineered bone (TEB) represents a promising approach to overcome these problems and is becoming an increasingly popular choice for repairing bone defects. Significant progress has been made toward scaffold materials for structural support with desired osteogenesis and angiogenesis abilities [5]. However, repair of bone defects over $30 \mathrm{~mm}$ using tissueengineering methods is a difficult clinical problem now [6].

Vascularization plays a very important role in skeletal development and repair [7]. It is crucial for TEB to establish a vascular network that temporally precedes the formation of new bone [8]. Because blood supply is restricted in its exterior portions without vascularization, cells face the lack of reliable oxygen and nutrient supply. In current surgical practice, tissues that need to be transferred from one part of the body to another as living three-dimensional constructs can be provided with a vasculature by prefabrication techniques [9]. Scaffolds including xenogenic bone mineral [10], poly(DLlactic-co-glycolic acid) (PLGA) [9], HA/ $\beta$-TCP granula [2], and processed bovine cancellous bone (PBCB) matrices [11] have been successfully vascularized with surgical angiogenesis skills, allowing transplantation to defect sites.

A new type of nano-hydroxyapatite/collagen/poly(Llactic acid) (nHAC/PLA) composite, similar to the natural bone in main composition and in hierarchical microstructure, has been fabricated before [12-15]. It possesses a porous microstructure with a pore size of about $100-300 \mu \mathrm{m}$ and a porosity of about $80 \%$ like cancellous bone. The cell culture and the implant experiment demonstrated that it was bioactive and could repair some small bone defects. The purpose of this study was to evaluate whether vascularized nHAC/PLA composites could be prefabricated in vivo. 


\section{Materials and Methods}

2.1. Materials. Synthesis of nHAC/PLA was prepared as previously described [12-15]. Type I collagen (CELLON Company, Strassen, Luxembourg) was diluted in deionized (DI) water at $0.67 \mathrm{~g}$ collagen $/ \mathrm{L}$ and room temperature for 3 hours. Solutions of $\mathrm{CaCl}_{2}$ and $\mathrm{H}_{3} \mathrm{PO}_{4}(\mathrm{Ca} / \mathrm{P}=1.66)$ were then separately added by drops. The solution was stirred and titrated with sodium hydroxide solution to $\mathrm{pH}$ 7.4 at room temperature. The nHAC deposition was harvested by centrifugation and freeze-dried after 48 hours. The nHAC powder was then distributed in the PLA matrix $\left(\mathrm{MW}=1.0 \times 10^{5} \mathrm{Da}\right.$; Shandong Medical Appliance Factory, Liaocheng, China) at a $1: 1$ weight ratio (nHAC/PLA). The mixture was frozen at $-20^{\circ} \mathrm{C}$ overnight and then lyophilized to remove dioxane. After ultrasonication, the material was fabricated into cylindrical slices $(\Phi=10 \mathrm{~mm} \times 10 \mathrm{~mm})$ with a hole of $1.5 \mathrm{~mm}$ diameter in the center.

2.2. Experimental Design. All experiments were approved by the animal ethics committee of Peking Union Medical College Hospital (PUMCH), and the procedures were conducted in accordance with the guidelines for the care and maintenance of animals. Fifteen three-month-old New Zealand rabbits (Experimental Animal Center of PUMCH, Beijing, China) weighing 2.5 to $3.0 \mathrm{~kg}$ were used. All operations were performed under sterile conditions by the same surgeon. An nHAC/PLA composite was directly implanted into the intramuscular gap with an arteriovenous (AV) bundle in the left groin (Group A), and another one was implanted into the intramuscular gap with an AV bundle in the right groin (Group B) after being mixed with the autologous bone marrow. Histological examinations were performed at 2, 6, and 10 weeks after implantation.

2.3. Surgical Procedures. The animals were anesthetized with an intravenous injection of 3\% pentobarbital sodium ( $1 \mathrm{~mL} / \mathrm{kg}$ body weight, Sigma, USA). 800,000 IU penicillin sodium (North China Pharmaceutical Group Corporation, China) was injected intramuscularly for preventing infection. Group A was treated as follows. Through a skin incision from the groin midpoint to the left knee, the femoral neurovascular bundle was exposed, and the nerve was protected. The left femoral artery and vein were surgically dissociated and then were transversely cut and ligatured at 2 to $3 \mathrm{~cm}$ under the femoral artery furcation for an AV bundle. The AV bundle was placed in the hole of the nHAC/PLA composite and was placed into the intramuscular gap. The femoral muscle and skin were sutured with 3-0 silk sutures. In Group B, the same procedures were performed after another nHAC/PLA composite was mixed with $10 \mathrm{~mL}$ autologous bone marrow from its tibia using a self-made device (Figure 1). Postoperatively, $800,000 \mathrm{IU}$ penicillin sodium and $0.15 \mathrm{mg}$ buprenorphine (Tianjin Institute of Pharmaceutical Research, China) were separately administered intramuscularly every 12 hours for 3 days.

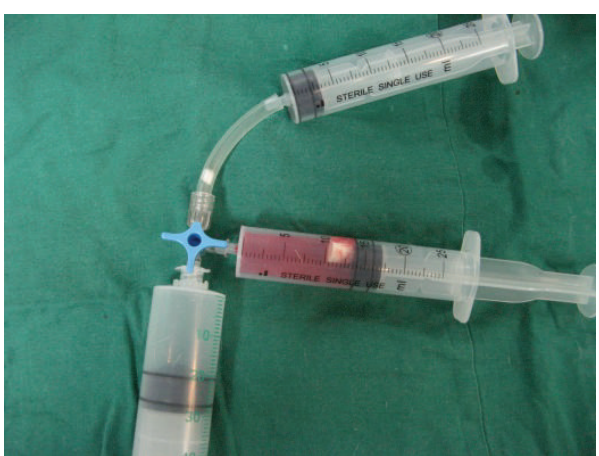

FIgURE 1: The self-made device for mixing bone marrow with an nHAC/PLA composite.

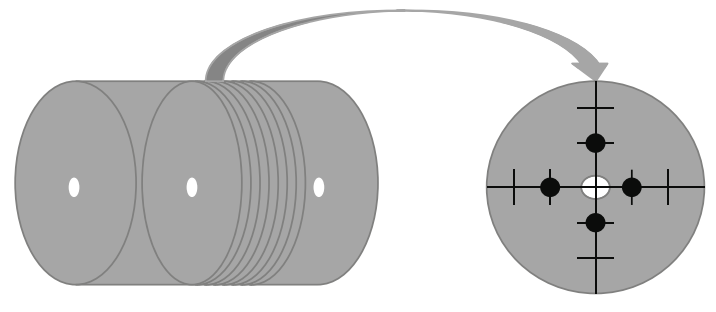

(a)

(b)

FIGURE 2: Schematic drawing demonstrating the approach to histological examinations: (a) 8 cross-sections were obtained perpendicular to the AV bundle in the middle; (b) 4 microphotographs of interest in the inner $1 / 3$ radius at $3,6,9$, and 12 o'clock at $400 \mathrm{x}$ magnification were evaluated for MVD (dark black points).

2.4. Histological Examinations. The animals were sacrificed after 2, 6, and 10 weeks ( $n=5$, resp.). The implants were removed and fixed in $10 \%$ buffered formalin for 24 hours. After washing, they were decalcified by $14 \%$ ethylenediaminetetraacetic acid (EDTA) solution for 6 weeks. Then, they were dehydrated in graded ethanols and embedded in paraffin. Eight cross-sections $(5 \mu \mathrm{m})$ were obtained from each specimen, perpendicular to the AV bundle in the middle (Figure 2(a)), using a Leica microtome (Leica Microsystems, Wetzlar, Germany). For histomorphometirc analysis, four sections were randomly selected for haematoxylin and eosin ( $\mathrm{H} \& \mathrm{E})$ staining, and microphotographs were taken using a microscope and a digital camera (Leica Microsystems). On each section, four microphotographs of interest in the inner $1 / 3$ radius at $3,6,9$, and $12 \mathrm{o}^{\prime}$ clock at $400 \mathrm{x}$ magnification were evaluated, and the number of vessels in high power field (HPF) was counted by two independent and blinded pathologists (Figure 2(b)). Microvessel density (MVD) was calculated for each group and each time point. One of the other sections was prepared for CD31 immunofluorescence histochemical staining with rabbit anti-PECAM-1 (primary antibody; Beijing Biosynthesis Biotechnology Corporation, China) and goat anti-rabbit IgG/FITC (second antibody; Beijing Biosynthesis Biotechnology Corporation, China) for qualitative assessment. 


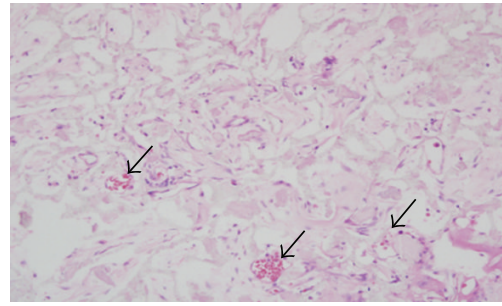

(a)

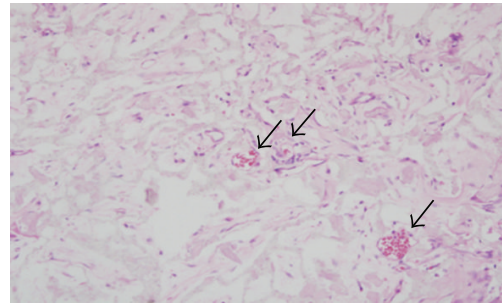

(d)

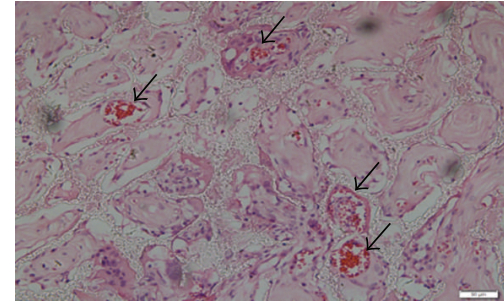

(b)

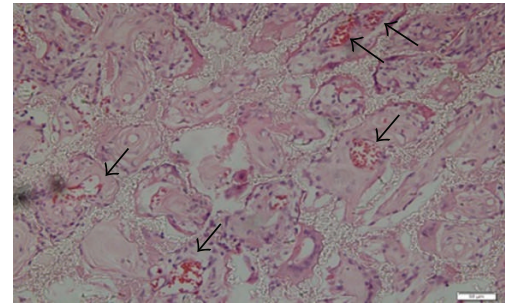

(e)

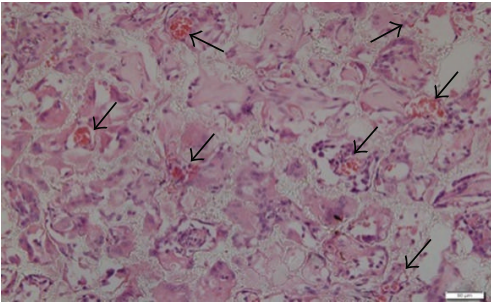

(c)

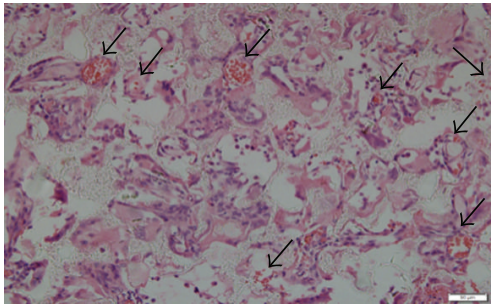

(f)

FIGURE 3: Hematoxylin and eosin (H\&E) staining of specimens (magnification $\times 200)$ : $(\mathrm{a} \sim \mathrm{c}) 2$, 6, and 10 weeks separately after implantation from Group A; (d f) 2, 6, and 10 weeks separately after implantation from Group B. Black arrows showed vessels.

2.5. Statistics Analysis. All results of MVD were given as means \pm standard deviation $(X \pm \mathrm{SD}$, vessels/HPF). Statistical analysis was performed using the paired samples Student's $t$-test with SPSS 16.0. The critical level of statistical significance was set at $P<0.05$.

\section{Results}

3.1. Surgery and Macroscopic Appearance. All 15 rabbits tolerated the surgical procedure and survived well. There were no major perioperative complications such as infection, hematomas, or wound dehiscence. No extrusion of the implants occurred over the observation period. The implants were surrounded by neighbouring tissue. At each time point, there was no significant difference of the mass around tissue and the blood supply of the implants between the two groups in the macroscopic appearance.

3.2. Histological Examinations. The newly formed tissue was composed predominantly of inflammatory cells, fibroblasts, blood vessels, and vascular sprouts in both groups (Figure 3). There was less tissue occupying the pores of nHAC/PLA in Group A than in Group B. Along with the time extension, there were fewer inflammatory cells and more fibroblasts and vessels. At 2 weeks later, MVD of the implants in both groups is similar $(9.35 \pm 1.58$ versus $9.08 \pm 2.18, P=0.712>0.05$, Figure 4). At 6 weeks later, MVD of the implants in Group A was significantly less than in Group B (15.60 \pm 3.20 versus $19.08 \pm 3.18, P<0.01$, Figure 4$)$. When explanting after 10 weeks, MVD of the implants in Group A was also significantly less than in Group B (18.19 \pm 3.17 versus 20.67 $\pm 3.78, P<0.01$, Figure 4$)$. There was a trend towards an increase in MVD in each group over time. The new vessels of the implants could be verified by using CD31 immunofluorescence histochemical staining (Figure 5).

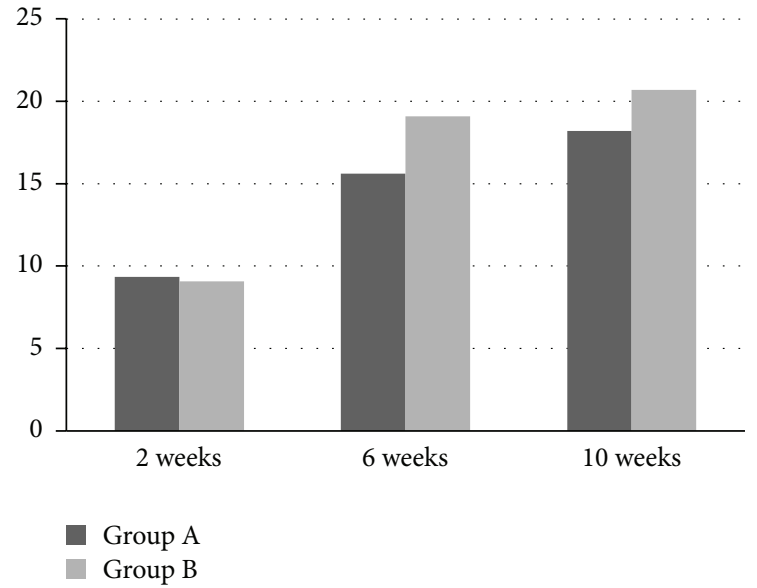

FIGURE 4: Quantification of microvessel density (MVD) between Group A and Group B. 2 weeks: no significant difference $(P>0.05)$; 6 and 10 weeks: significant difference $(P<0.01)$.

The vascular walls and red blood cells showed remarkable light green fluorescence. By 10 weeks, more new vessels were observed in Group B than Group A.

\section{Discussion}

Vascularization plays an important role in the process of osteogenesis, both in development and during repair. Osteogenesis is characterized by invasion of capillaries into the mesenchymal zone and the differentiation of mesenchymal cells into mature osteoblasts, which deposit bone matrix and lead to the formation of bone [16]. Diffusion limits oxygen and nutrition supply to a maximum range of $200 \mu \mathrm{m}$ into a given matrix [17]. Cells cannot survive in the large constructs 


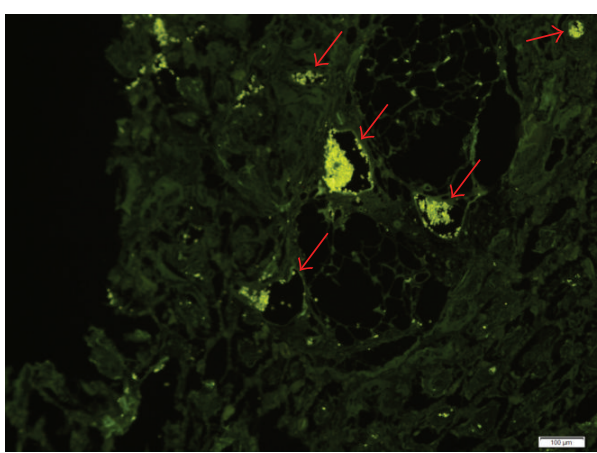

(a)

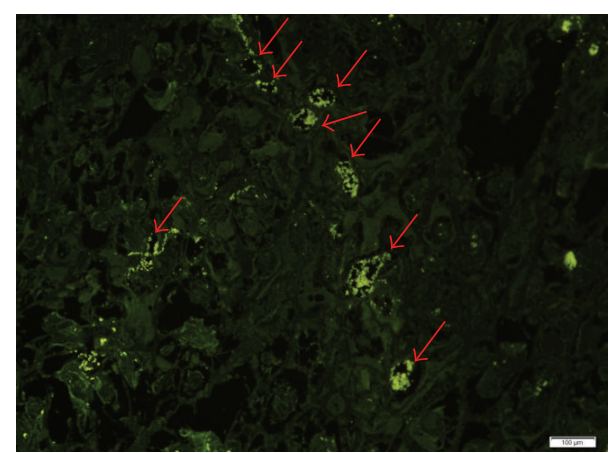

(b)

FIGURE 5: CD31 immunofluorescence histochemical staining of specimens 10 weeks after implantation (magnification $\times 100)$ : the vascular walls and red blood cells display remarkable light green fluorescence: (a) from Group A, (b) from Group B. Red arrows showed vessels.

without vascularization after they are transferred in vivo environment.

TEB, an alternative to autologous bone, allogenic and xenogenic bone grafts may overcome their shortcomings such as limited availability for harvest, donor-site morbidity, and disease transmission [2, 3]. It has become technically feasible to repair small sized bone defects in clinical practice, but it still remains challenging for reconstruction of large volume defects [18].

The nHAC/PLA composite fabricated before, as one of TEBs, has been demonstrated that it was similar to the natural bone in main composition and in hierarchical microstructure [12]. Previous studies showed that it was bioactive and could repair some small bone defects [15]. However, there was no experiment about its ability of vascularization for repairing large defects so far. In this study, we first demonstrated that the nHAC/PLA composite could be vascularized in vivo.

At present, there are three methods to achieve the vascularization of tissue: incorporation of angioinductive growth factors, endothelial cells coculture, and surgical techniques [7]. The vessels of a construct by incorporating endothelial cells are not mature and stable [19]. Delivery of angiogenic factors can only enhance the formation of new vessels [20, 21]. Recently, surgical angiogenesis, utilizing preexisting blood vessels as a vascular carrier and to incorporate artificial materials and cells into them to regenerate nutrient vessels, has become a promising method to establish a functional vascular network.

The extrinsic vascular pathway, originating from the periphery of the construct by implanting into a site of high vascularization potential (subcutaneous [22], intramuscular [23], and intraperitoneal [24]), has become the most frequent method of vascularization in tissue engineering and has been available for clinical practice [25]. The disadvantage of this pathway is that the vascular network is random and will be destroyed while transferring to distant implantation sites. For this reason, axial vascularization (the intrinsic vascular pathway), originating from implanted vessels, has been proposed by reconstructive surgeons [18].

The methods of axial vascularization included AV shunt loop, distal ligation type AV bundle, and flow-through type
AV bundle. After comparing them, although the AV shunt loop showed a greater potential for producing new tissue and capillaries, the distal ligation type AV bundle was thought to be more effective and feasible as a vascular carrier [26]. Up to now, AV bundle has been applied clinically [27], but no application of AV shunt loops has been reported. The AV bundle is simpler to be constructed operatively than the AV shunt loop, does not present problems with thrombus formation, and provides stable blood flow [26]. Hence, distal ligation type AV bundle was chosen as axial vessels in this study. The results of this study showed that AV bundle could induce axial vascularization of nHAC/PLA composites. An nHAC/PLA composite after prefabrication in vivo could be transplanted as a free flap or a pedicle flap to a bone defect.

In the past decade, researchers have gained important insights into the role of bone marrow derived cells in adult neovascularization. A subset of bone marrow derived cells, called endothelial progenitor cells, has been of particular interest, as these cells were suggested to home to sites of neovascularization and neoendothelialization and differentiate into endothelial cells in situ, a process referred to as postnatal vasculogenesis [28]. In this study, it was confirmed that the vascularization of $\mathrm{nHAC} / \mathrm{PLA}$ composites with $\mathrm{AV}$ bundle could be significantly enhanced by autologous bone marrow in the middle and later phases. Meanwhile, there was no risk of rejection by autografting. So it was an ideal method to prefabricate a vascularized nHAC/PLA composite with the combination of AV bundle and autologous bone marrow.

In conclusion, nHAC/PLA composites, implanted intramuscularly with AV bundles, had been shown to generate new vascular networks for prefabrication of large bone substitutes. The vascularization was better in combination with autologous bone marrow than without it and was more suitable for the microsurgery transplanting. Osteoinduction of microstructured calcium phosphate materials and multiwalled carbon nanotubes (MWNTs) has been shown in soft tissues by concentrating more proteins to differentiate inducible cells to osteogenic cells [29-31]. In the future, the osteoinduction of nHAC/PLA composites in soft tissues should be investigated to decide the possibility of ectopic fabrication of large volume vascularized TEB in combination 
with recombinant human bone morphogenetic protein-2 (rhBMP-2) or osteogenic protein-1 (OP-1).

\section{Authors' Contribution}

Hai Wang and Xiao Chang are co-first authors.

\section{Acknowledgment}

This paper is sponsored by the National Natural Science Foundation of china under Contract Grant no. 81000802.

\section{References}

[1] J. P. Beier, A. Hess, J. Loew et al., "De novo generation of an axially vascularized processed bovine cancellous-bone substitute in the sheep arteriovenous-loop model," European Surgical Research, vol. 46, no. 3, pp. 148-155, 2011.

[2] J. P. Beier, R. E. Horch, A. Hess et al., "Axial vascularization of a large volume calcium phosphate ceramic bone substitute in the sheep AV loop model," Journal of Tissue Engineering and Regenerative Medicine, vol. 4, no. 3, pp. 216-223, 2010.

[3] A. J. Aho, T. Ekfors, P. B. Dean, H. T. Aro, A. Ahonen, and V. Nikkanen, "Incorporation and clinical results of large allografts of the extremities and pelvis," Clinical Orthopaedics and Related Research, no. 307, pp. 200-213, 1994.

[4] X. M. Li, Y. Yang, Y. B. Fan, Q. L. Feng, F. Z. Cui, and F. Watari, "Biocomposites reinforced by fibers or tubes, as scaffolds for tissue engineering or regenerative medicine," Journal of Biomedical Materials Research Part A, 2013.

[5] X. M. Li, L. Wang, Y. B. Fan, Q. L. Feng, F. Z. Cui, and F. Watari, "Nanostructured scaffolds for bone tissue engineering," Journal of Biomedical Materials Research Part A, vol. 101, no. 8, pp. 24242435, 2013.

[6] X. Li, Q. Feng, X. Liu, W. Dong, and F. Cui, "Collagen-based implants reinforced by chitin fibres in a goat shank bone defect model," Biomaterials, vol. 27, no. 9, pp. 1917-1923, 2006.

[7] L.-L. Ren, D.-Y. Ma, X. Feng, T.-Q. Mao, Y.-P. Liu, and Y. Ding, "A novel strategy for prefabrication of large and axially vascularized tissue engineered bone by using an arteriovenous loop," Medical Hypotheses, vol. 71, no. 5, pp. 737-740, 2008.

[8] H. Yu, P. J. VandeVord, L. Mao, H. W. Matthew, P. H. Wooley, and S.-Y. Yang, "Improved tissue-engineered bone regeneration by endothelial cell mediated vascularization," Biomaterials, vol. 30, no. 4, pp. 508-517, 2009.

[9] S. O. P. Hofer, K. M. Knight, J. J. Cooper-White et al., "Increasing the volume of vascularized tissue formation in engineered constructs: an experimental study in rats," Plastic and Reconstructive Surgery, vol. 111, no. 3, pp. 1186-1192, 2003.

[10] H. Kokemueller, S. Spalthoff, M. Nolff et al., "Prefabrication of vascularized bioartificial bone grafts in vivo for segmental mandibular reconstruction: experimental pilot study in sheep and first clinical application," International Journal of Oral and Maxillofacial Surgery, vol. 39, no. 4, pp. 379-387, 2010.

[11] U. Kneser, E. Polykandriotis, J. Ohnolz et al., "Engineering of vascularized transplantable bone tissues: induction of axial vascularization in an osteoconductive matrix using an arteriovenous loop," Tissue Engineering, vol. 12, no. 7, pp. 1721-1731, 2006.

[12] S. S. Liao, F. Z. Cui, W. Zhang, and Q. L. Feng, "Hierarchically biomimetic bone scaffold materials: nano-HA/collagen/PLA composite," Journal of Biomedical Materials Research Part B, vol. 69, no. 2, pp. 158-165, 2004.

[13] C. Du, F. Z. Cui, W. Zhang, Q. L. Feng, X. D. Zhu, and K. de Groot, "Formation of calcium phosphate/collagen composites through mineralization of collagen matrix," Journal of Biomedical Material Research, vol. 50, no. 4, pp. 518-527, 2000.

[14] C. Du, F. Z. Cui, X. D. Zhu, and K. de Groot, "Threedimensional nano-HAp/collagen matrix loading with osteogenic cells in organ culture," Journal of Biomedical Material Research, vol. 44, no. 4, pp. 407-415, 1999.

[15] J. Li, J. Hong, Q. Zheng et al., "Repair of rat cranial bone defects with nHAC/PLLA and BMP-2-related peptide or rhBMP-2," Journal of Orthopaedic Research, vol. 29, no. 11, pp. 1745-1752, 2011.

[16] J. M. Kanczler and R. O. C. Oreffo, "Osteogenesis and angiogenesis: the potential for engineering bone," European Cells and Materials, vol. 15, pp. 100-114, 2008.

[17] A. Arkudas, J. P. Beier, K. Heidner et al., "Axial prevascularization of porous matrices using an arteriovenous loop promotes survival and differentiation of transplanted autologous osteoblasts," Tissue Engineering, vol. 13, no. 7, pp. 1549-1560, 2007.

[18] U. Kneser, D. J. Schaefer, E. Polykandriotis, and R. E. Horch, "Tissue engineering of bone: the reconstructive surgeon's point of view," Journal of Cellular and Molecular Medicine, vol. 10, no. 1, pp. 7-19, 2006.

[19] R. K. Jain, P. Au, J. Tam, D. G. Duda, and D. Fukumura, "Engineering vascularized tissue," Nature Biotechnology, vol. 23, no. 7, pp. 821-823, 2005.

[20] Y.-C. Huang, D. Kaigler, K. G. Rice, P. H. Krebsbach, and D. J. Mooney, "Combined angiogenic and osteogenic factor delivery enhances bone marrow stromal cell-driven bone regeneration," Journal of Bone and Mineral Research, vol. 20, no. 5, pp. 848-857, 2005.

[21] R. Hou, F. Chen, Y. Yang et al., "Comparative study between coral-mesenchymal stem cells-rhBMP-2 composite and autobone-graft in rabbit critical-sized cranial defect model," Journal of Biomedical Materials Research Part A, vol. 80, no. 1, pp. 85-93, 2007.

[22] U. Kneser, A. Voogd, J. Ohnolz et al., "Fibrin gel-immobilized primary osteoblasts in calcium phosphate bone cement: in vivo evaluation with regard to application as injectable biological bone substitute," Cells Tissues Organs, vol. 179, no. 4, pp. 158169, 2005.

[23] J. P. Beier, U. Kneser, J. Stern-Sträter, G. B. Stark, and A. D. Bach, "Y chromosome detection of three-dimensional tissueengineered skeletal muscle constructs in a syngeneic rat animal model," Cell Transplantation, vol. 13, no. 1, pp. 45-53, 2004.

[24] U. Kneser, P. M. Kaufmann, H. C. Fiegel, and X. Rogiers, "Longterm differentiated function of heterotopically transplanted hepatocytes on three-dimensional polymer matrices," Journal of Biomedical Material Research, vol. 47, no. 4, pp. 494-503, 1999.

[25] P. Warnke, I. Springer, P. J. Wiltfang et al., "Growth and transplantation of a custom vascularised bone graft in a man," The Lancet, vol. 364, no. 9436, pp. 766-770, 2004.

[26] Y. Tanaka, K.-C. Sung, A. Tsutsumi, S. Ohba, K. Ueda, and W. A. Morrison, "Tissue engineering skin flaps: which vascular carrier, arteriovenous shunt loop or arteriovenous bundle, has more potential for angiogenesis and tissue generation?" Plastic and Reconstructive Surgery, vol. 112, no. 6, pp. 1636-1644, 2003. 
[27] J. J. Pribaz, N. Fine, and D. P. Orgill, "Flap prefabrication in the head and neck: a 10-year experience," Plastic and Reconstructive Surgery, vol. 103, no. 3, pp. 808-820, 1999.

[28] F. Timmermans, J. Plum, M. C. Yöder, D. A. Ingram, B. Vandekerckhove, and J. Case, "Endothelial progenitor cells: identity defined?" Journal of Cellular and Molecular Medicine, vol. 13, no. 1, pp. 87-102, 2009.

[29] X. Li, C. A. van Blitterswijk, Q. Feng, F. Cui, and F. Watari, “The effect of calcium phosphate microstructure on bone-related cells in vitro," Biomaterials, vol. 29, no. 23, pp. 3306-3316, 2008.

[30] X. Li, H. Liu, X. Niu et al., "The use of carbon nanotubes to induce osteogenic differentiation of human adipose-derived MSCs in vitro and ectopic bone formation in vivo," Biomaterials, vol. 33, no. 19, pp. 4818-4827, 2012.

[31] X. Li, H. Gao, M. Uo et al., "Effect of carbon nanotubes on cellular functions in vitro," Journal of Biomedical Materials Research Part A, vol. 91, no. 1, pp. 132-139, 2009. 

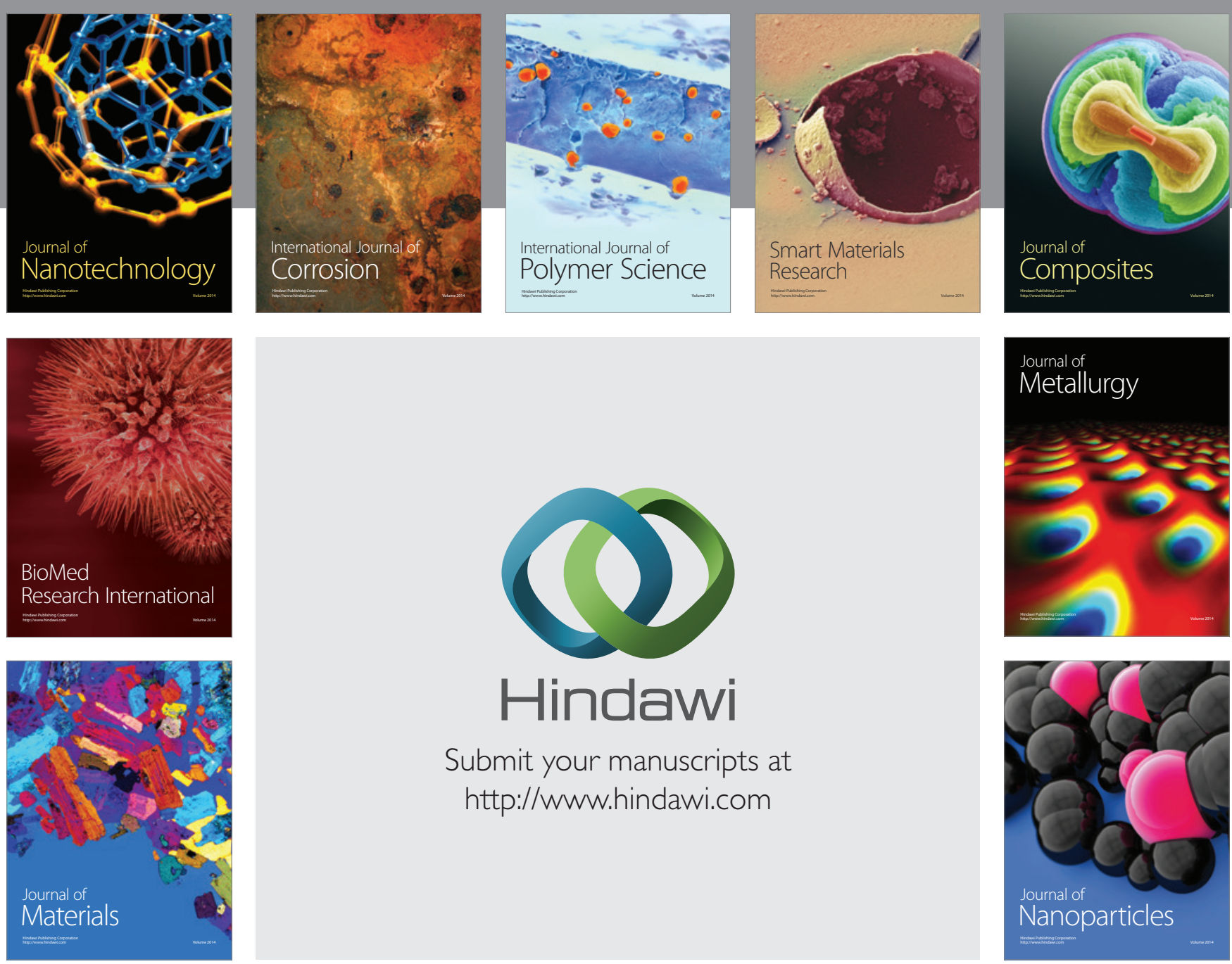

Submit your manuscripts at http://www.hindawi.com
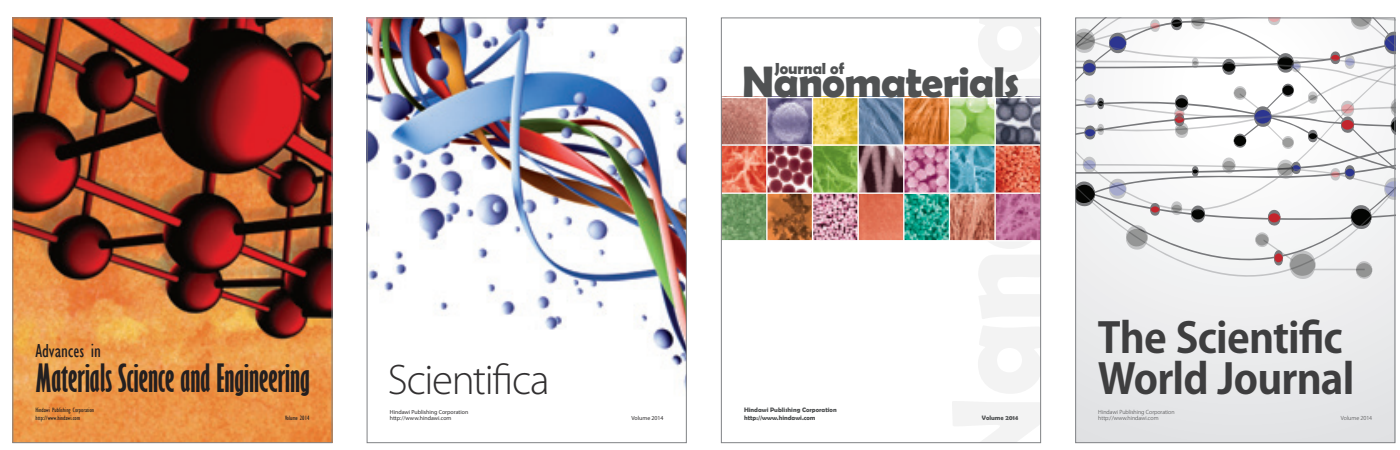

\section{The Scientific World Journal}
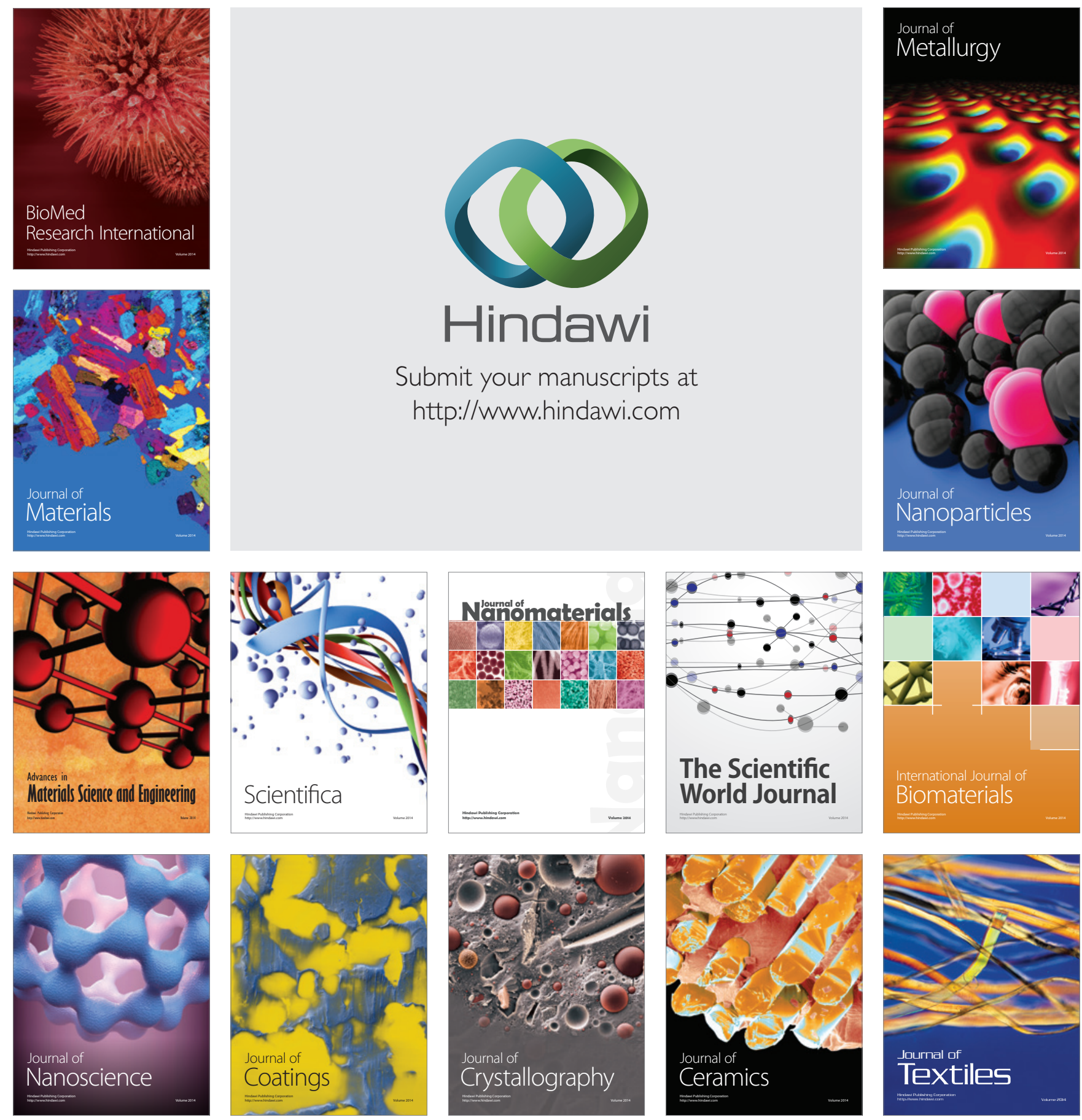